\title{
Shades of darkness or Light? A Systematic Review of Geographic Bias in Impact Evaluations of Electricity Access
}

\author{
Accepted for publication with Energy Research \& Social Science
}

\begin{tabular}{|c|c|c|c|c|c|}
\hline $\begin{array}{c}\text { David } \\
\text { Hamburger }\end{array}$ & Joel Jaeger & $\begin{array}{l}\text { Patrick } \\
\text { Bayer }^{*}\end{array}$ & $\begin{array}{c}\text { Ryan } \\
\text { Kennedy }\end{array}$ & $\begin{array}{c}\text { Joonseok } \\
\text { Yang }\end{array}$ & $\begin{array}{l}\text { Johannes } \\
\text { Urpelainen }\end{array}$ \\
\hline $\begin{array}{c}\text { Johns Hopkins } \\
\text { SAIS }\end{array}$ & $\begin{array}{c}\text { Johns Hopkins } \\
\text { SAIS }\end{array}$ & $\begin{array}{l}\text { University of } \\
\text { Strathclyde }\end{array}$ & $\begin{array}{l}\text { University of } \\
\text { Houston }\end{array}$ & $\begin{array}{l}\text { Columbia } \\
\text { University }\end{array}$ & $\begin{array}{c}\text { Johns } \\
\text { Hopkins SAIS }\end{array}$ \\
\hline
\end{tabular}

\begin{abstract}
Despite the growing use of impact evaluations for electrification interventions, little attention has been paid to the geographical distribution of such evaluations. This is concerning because cultural and regional differences may limit how transferable results across regions are. We undertake a systematic review of the literature and find $31 \mathrm{impact}$ evaluations of electricity access in 16 countries that meet our criteria for statistical hypothesis testing of development outcomes. India accounts for a quarter of the impact evaluations. Given the large non-electrified population in India, this is still a small number, roughly comparable to Nigeria or Kenya. South Asia and sub-Saharan Africa are the most underrepresented regions. We find more positive impacts from electricity access, on average, for South Asia than for sub-Saharan Africa, which calls for greater attention to geographical bias in future impact evaluations of electrification access.
\end{abstract}

Keywords: Electricity access; energy poverty; impact evaluation; electrification; development; geographical distribution; systematic review.

\footnotetext{
${ }^{*}$ Corresponding author. Address: University of Strathclyde, McCance Building, 16 Richmond Street, Glasgow, G1 1QX, Scotland, UK. Email: patrick.bayer@strath.ac.uk
} 


\section{Introduction}

An estimated one billion people globally lack access to electricity (World Bank 2017). Although access remains a challenge in parts of Latin America, the Middle East, and South East Asia, the overwhelming majority of the non-electrified population is concentrated in sub-Saharan Africa (SSA) and South Asia. Making progress towards Sustainable Development Goal 7 of universal energy access by 2030 requires "urgent measures" to improve electrification worldwide (World Bank 2017).

As attempts to address this energy access challenge continue, impact evaluationsexaminations of policy interventions comparing both against pre-intervention and nointervention cases-offer a rigorous way for determining the effectiveness and benefits of electrification interventions. In this paper, we analyze the regional focus in the existing set of impact evaluations of electrification access. We compare the number of studies from various regions to the non-electrified population in the same regions to identify to what extent impact evaluations of electrification access are geographically concentrated. Indeed, we do find evidence for geographical bias from regional clustering.

Regional clustering is important as differences across regions may limit how transferable results from impact evaluations are. Our work complements research that has alerted scholars not only to the lack of rigorous impact evaluations for rural electrification (Bernard 2012) but also to the limited transferability of impacts of electricity access from, in particular, Asia to sub-Saharan Africa (Peters and Sievert 2016). Our systematic review however goes beyond these existing works by documenting regional clustering in electricity access impact evaluations across all developing countries around the world and by translating how regional clustering affects the assessed outcomes and impacts. While others show that the chosen method (e.g., observational versus experimental methods) matters for impact assessment (Bayer et al. 2019), this paper focuses on understanding the extent of geographical bias in the electricity access literature. This is key for building an effective body of scholarship to guide policy development. Addressing the electricity access challenge requires both researchers and funding agencies to acknowledge geographical bias and actively promote regional diversification in impact evaluation work.

The paper is divided into four main parts. First, we review the existing impact evaluation literature and discuss how geographical heterogeneity may limit the generalizability of results. We then describe the research design for our systematic review and present results from comparing impact evaluation studies by country and region along various dimensions: the number of studies, assessed outcomes, and evaluated impacts. The conclusion explores lessons for future impact evaluations and highlights the importance of geographic bias for study design and electricity access scholarship.

\section{Impact Evaluation and Electricity Access}

Impact evaluations are gaining currency as a robust method of assessing the effects of an implemented policy. Going beyond traditional before-and-after analysis, an impact 
evaluation typically compares the effect of a policy on a 'treated' group against a 'control' group (Waddington et al. 2018). So far, few impact evaluations have focused on electricity access (Bernard 2012), and experimental research designs that would allow for more robust inference for policy development are still scarce (Bayer et al. 2019).

Impact evaluations are conducted all across the developing world, and this geographic variation poses an additional challenge to evidence-based policy-making: regional or country-specific conditions limit how well findings travel from one case to the next. Likewise, if a policy fails to produce the desired impacts this could be because of a poorly designed policy itself or because of impeding local or regional factors. With only a limited set of studies from any given country or region, it is impossible to distinguish between the two causes of policy failure.

There is plenty of evidence that policy impacts differ across countries and regions. Lawry et al. (2016) find markedly more positive effects from a land reform policy in Asia and Latin America relative to sub-Saharan Africa. Regional differences are also recognized in a recent study of water supply in Nepal in an otherwise Africa-heavy body of impact evaluations (Vijayaraghavan and Kilroy 2018).

The impact evaluation literature on electricity access has only recently started to confront these challenges. In the most notable paper on regional representativeness to date, Peters and Sievert (2016) highlight that despite existing studies in Latin America, South Africa, and Asia, only a handful of impact evaluations of rural electrification exist for lessdeveloped countries in sub-Saharan Africa-even though the majority of the global nonelectrified population, on a per capita basis, lives there. This casts doubt on whether, for example, educational benefits from electricity access that are documented elsewhere (Khandker et al. 2012; Samad et al. 2013; Barron and Torero 2014) travel to sub-Saharan Africa or not, not least due to already high adoption of LED lights in the region (Bensch et al. 2017).

Cultural and societal factors are important for the benefits from electricity access to materialize. Continued use of kerosene lamps in Bangladesh and India despite access to cleaner electric lighting has been associated with the perception of solar lighting (Khandker et al. 2014; Mural et al. 2015). Social dynamics in rural communities and families greatly affect the benefits from electricity access (e.g., Grogan 2016; Salmon and Tanguy 2016; Furukawa 2014), with benefits for women often found to be smaller than for men (Pueyo and Maestre 2019). Implementing even the very same policy in a different geography can easily overturn the policy's impacts because of cultural and social differences.

Despite a trend towards greater use of impact evaluations by development organizations, such as the World Bank, IADB, or ADB (Crespo and Herrera 2017; Vijayaraghavan and Kilroy 2018; World Bank 2013; ADB 2012), there is generally little guidance on how to account for regional and contextual heterogeneity and how to examine the possibility of how results generalize beyond the often narrow study context. Answering to Peters and Sievert's (2016) call for greater attention to regional heterogeneity in impact evaluation 
studies requires taking stock of the geographical distribution of energy access research around the developing world. We introduce a systematic review approach as a rigorous, robust, and replicable methodology to energy research (Sovacool et al. 2018) for combing through the existing electricity access literature in order to identify the countries in which impact evaluations are taking place.

\section{Systematic Review of Electricity Access Studies}

To assess the geographic distribution of existing electricity access studies, we performed a systematic review of impact evaluations in the developing world. Here, we define a study as an 'impact evaluation' that assesses the socio-economic impacts of electricity access, independent of the particular research method that is used to obtain these results. Our sample contains studies using regression models, instrumental variable (IV) estimation, difference-in-differences (DID) designs, and experimental randomized controlled trials (RCTs).

The basic idea of a systematic review is to offer a rigorous, robust, and replicable methodology to select studies from a large universe by sequential filtering according to some inclusion criteria. Obviously, changing the inclusion requirements changes the sample of studies we end up with. Compared to the more informal literature review, where selection criteria are unclear, transparency about the inclusion criteria in a systematic review ensures replicability because of a more formal, "algorithmic" procedure.

In our case, where we are interested in a systematic review of impact evaluation studies of electricity access, we started with a simple, top-down search in Google Scholar, ScienceDirect, and Web of Science for any article since 2000 that comes up for the following search string: ("rural electrification" or "electricity" or "off-grid" or "solar") AND ("impact" or "effect" or "development" or "benefit"). We are completely agnostic here to any particular type of research method and seek to avoid publication bias by including both peer reviewed and non-peer reviewed studies, such as working papers or development bank reports, into our search. The initial universe leaves us with 7247 studies.

We now applied several filters to this universe of studies to identify those studies that reasonably qualify as impact evaluations of household electricity access in developing countries. Our choice of filters was guided by identifying studies that can not only demonstrate that a policy intervention works but that can also offer insight into how sizable a policy's effect is to inform evidence-based policymaking. In view of the universal energy access challenge articulated in SDG 7, we seek to identify the most robust and promising impact evaluations to address energy poverty around the globe.

First, based on title and abstract, we removed studies that dealt with engineering, technological, or political aspects of rural electrification rather than impact assessment, leaving us with 514 studies. The second filter removed another 231 studies for not focusing on impact assessment of electricity access based on a reading of the full text. The next two filters excluded studies that either only described (rather than assessed) 
impacts from electricity access or assessed them in a qualitative way based on personal impressions of the researcher instead of more objectively comparable measures of impacts. We therefore require studies in our sample to conduct a statistical hypothesis test of the impacts from electricity access, while descriptive, quasi-experimental, and experimental methods are all equally permissive. This brings the sample down to 46 studies, from which we include another four because they are literature reviews. The final filter then limits the studies to the household level and requires studies to assess one of the following five socio-economic development impacts: energy expenditure, household income, household savings, business creation, and education.

To more fully exhaust the academic literature on impact evaluations of electricity access, we combine these 15 studies that we are left with from the above described top-down search with a bottom-up search. This bottom-up search is based on screening the bibliographies of and reviewing the identified studies.

Overall, the systematic review results in 31 studies from the initial universe and these studies are listed in Appendix A. Importantly, the sample we end up with here is obviously conditional on the filters we chose and setting different filters would have resulted in a different sample. As long as these filters are however chosen in a transparent way and make sense in view of the research question, this is a strength and not a weakness of the systematic review approach. The result of the filtering process in our case is indeed a small number of studies, yet this is also not uncommon for systematic reviews. Modern search engines allow researchers to access thousands of studies, many of which are tangential to the specific research question and therefore should be excluded from the analysis.

To illustrate how the filters work in practice, let us consider a couple of studies that might seem relevant to electricity access impacts in the developing world which do however not pass our inclusion criteria. A recent study by Bensch et al. (2018), not included into our sample, assesses the adoption of solar home systems in Burkino Faso, which is not one of our five target outcome measures. Stojanowski et al. (2018) study the effect of solar lanterns on educational outcomes, which we do assess, yet their study evaluates impacts at the school, not household level, as we do. These two simple examples should help the reader to better understand the filtering process and to appreciate the trade-offs that sequential filtering involves.

The goal of a systematic review is not to aim for a specific total number of studies, but to identify filters that are justified by the research question and then to let the filtering do the work. Assuming informative filters are chosen, a small number of resulting studies from a systematic review is not a problem, but rather an important result by itself-exactly because of the formal, algorithmic procedure. The small number of studies we find is the output of our research rather than an input in the systematic review.

Few studies pass our filters of rigorous, household-level impact evaluations not because the filters are particularly unreasonable, but because few such studies exist. The small number of studies is hence not a flawed outcome of the systematic review; instead, it is 
a result of a lack of rigorous impact evaluations of electricity access, which has been noted by others as well (Bernhard 2012).

\section{Results}

We use our created sample of 31 impact evaluation studies to assess the geographic distribution of these studies. For this, we group countries into four world regions-Latin America and the Caribbean (LAC), South Asia, South East Asia, or sub-Saharan Africa (SSA).

We present several sets of results below. First, we simply count the number of impact evaluations that are done in each county and region and then standardize counts by unelectrified population for a relative measure. Second, we show to what extent the sites in any country for which impact evaluations were done are representative within the country of study itself as well as across countries in the developing world. Third, we analyze the relative frequency of assessed outcomes of the impact evaluations across countries and regions (i.e., energy expenditure, household income, household savings, business creation, and education). We finally create a weighted impact score to see whether some countries or regions are prone to more positive impacts.

\subsection{Study Count}

Based on our systematic review, the 31 impact evaluations of electricity access, which we identify, have been conducted in only 16 different countries. Figure 1 shows the geographic distribution of studies in the developing world.

Figure 1: Geographic distribution of impact evaluations of energy access

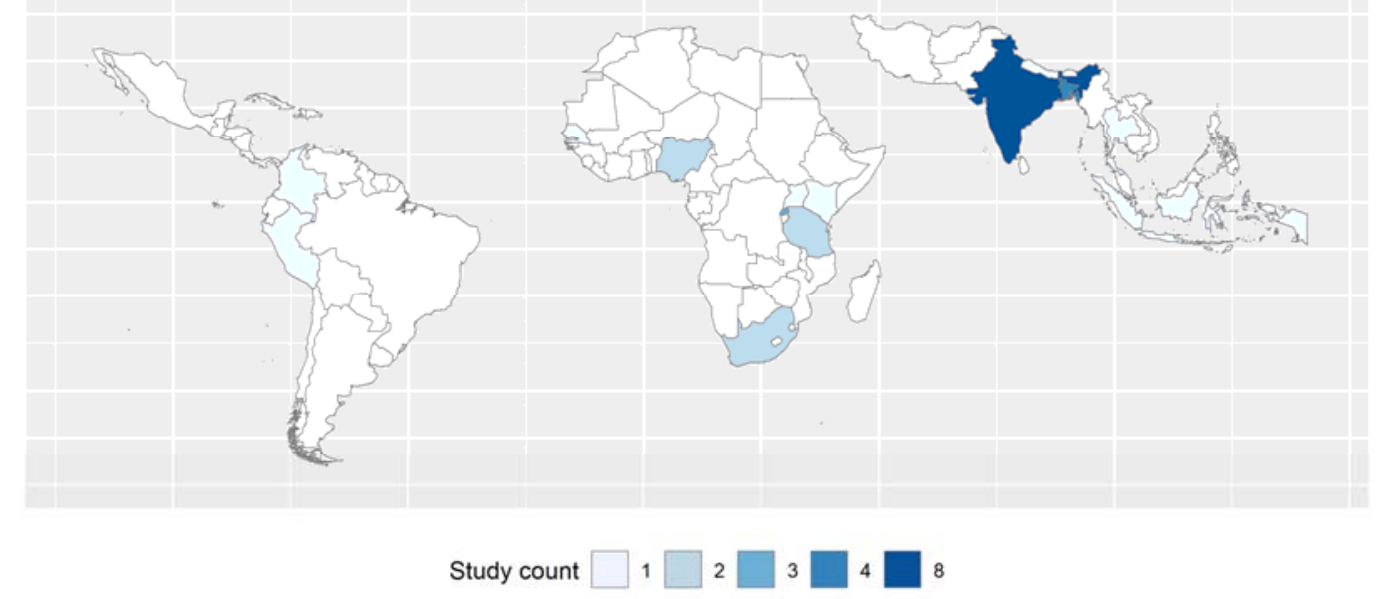

\footnotetext{
* Latin America and Caribbean includes studies in Colombia, El Salvador, and Peru; South Asia includes studies from India, Bangladesh, and Nepal; South East Asia includes Indonesia, Thailand and Vietnam; and sub-Saharan Africa includes Rwanda, Senegal, South Africa, Nigeria, Kenya, Tanzania, and Uganda.
} 
As shown in Table 1 below, ten of the 16 countries in our sample were the subject in only a single study. There have been two studies each in South Africa, Nigeria, and Tanzania, three studies in Rwanda, four studies in Bangladesh, and eight studies in India, the most of any country. India hence accounts for a quarter of what we know about the impacts from electricity access.

Table 1: Study count by country, with additional information on electrification

\begin{tabular}{|c|c|c|c|c|c|c|}
\hline \multirow[t]{2}{*}{$\#$} & \multirow[t]{2}{*}{ Country } & \multirow[t]{2}{*}{ Region } & \multirow[t]{2}{*}{ Count } & \multirow[t]{2}{*}{ Elec rate } & \multicolumn{2}{|c|}{ Population (million) } \\
\hline & & & & & nominal & unelectrified \\
\hline 1 & India & South Asia & 8 & $79 \%$ & 1339.1 & 281.2 \\
\hline 2 & Bangladesh & South Asia & 4 & $62 \%$ & 164.6 & 62.5 \\
\hline 3 & Rwanda & SSA & 3 & $20 \%$ & 12.2 & 9.7 \\
\hline 4 & South Africa & SSA & 2 & $86 \%$ & 56.7 & 7.9 \\
\hline 5 & Nigeria & $\mathrm{SSA}$ & 2 & $58 \%$ & 190.8 & 80.1 \\
\hline 6 & Tanzania & SSA & 2 & $16 \%$ & 57.3 & 48.1 \\
\hline 7 & Colombia & $\mathrm{LAC}$ & 1 & $98 \%$ & 49.0 & 0.9 \\
\hline 8 & El Salvador & $\mathrm{LAC}$ & 1 & $98 \%$ & 6.3 & 0.1 \\
\hline 9 & Indonesia & South East Asia & 1 & $97 \%$ & 263.9 & 7.9 \\
\hline 10 & Kenya & SSA & 1 & $36 \%$ & 49.6 & 31.8 \\
\hline 11 & Nepal & South Asia & 1 & $85 \%$ & 29.3 & 4.3 \\
\hline 12 & Peru & $\mathrm{LAC}$ & 1 & $93 \%$ & 31.1 & 2.2 \\
\hline 13 & Senegal & SSA & 1 & $61 \%$ & 15.8 & 9.6 \\
\hline 14 & Thailand & South East Asia & 1 & $100 \%$ & 69.0 & 0.0 \\
\hline 15 & Uganda & $\mathrm{SSA}$ & 1 & $20 \%$ & 42.8 & 34.2 \\
\hline 16 & Vietnam & South East Asia & 1 & $99 \%$ & 9.5 & 0.1 \\
\hline
\end{tabular}

Notes: Electrification rates come from the Global Tracking Framework (2017); Population data come from World Bank Development Indicators (2017), and non-electrified population is calculated from these data. SSA=sub-Saharan Africa; LAC=Latin America and Caribbean.

On the regional level, impact evaluations are not evenly spread geographically. South Asia and sub-Saharan Africa dominate research, with more than ten studies each. Only three studies each were conducted in South East Asia and Latin American and the Caribbean. Given that South Asia and sub-Saharan Africa are home to the vast majority of non-electrified populations, this focus is not too surprising.

Table 2: Study count by region, with additional information on electrification

\begin{tabular}{llrrrr}
\hline$\#$ & Region & Count & Elec rate & \multicolumn{2}{c}{ Population (million) } \\
& & & nominal & unelectrified \\
\hline 1 & South Asia & 13 & $81.7 \%$ & 1788.3 & 327.2 \\
2 & SSA & 12 & $46.9 \%$ & 1061.1 & 563.4 \\
3 & South East Asia & 3 & $97.6 \%$ & 641.7 & 55.1 \\
4 & LAC & 3 & $96.1 \%$ & 644.1 & 19.3 \\
\hline
\end{tabular}

Notes: Electrification rates come from the Global Tracking Framework (2017); Population data come from World Bank Development Indicators (2017), and non-electrified population is calculated from these data. SSA=sub-Saharan Africa; LAC=Latin America and Caribbean. 


\subsection{Study Count by Non-Electrified Population}

So far, we only looked at the total number of studies without accounting for how severe the problem of non-electrification in a given country and region is. Standardizing study counts by the number of non-electrified population, we obtain a more accurate measure of the electrification challenge.

By this measure, El Salvador, Colombia, Vietnam, and Thailand are relatively overrepresented. With one study each, this is however not because there are many studies done on these countries, but rather because their non-electrified populations are small. El Salvador and Colombia are $98 \%$ electrified, Vietnam is $99 \%$ electrified, and Thailand is $100 \%$ electrified, so all four countries have essentially overcome the electrification challenge.

Based on countries in our sample, India has few studies on a per capita basis. With a non-electrified population of 281 million people, even the eight studies that have been carried out are a small number. Nigeria is under-researched even more: for its massive population of 190 million non-electrified citizens we could only identify two studies in our sample.

Notably, there are countries without a single impact evaluation. These are therefore less well represented still. The Democratic Republic of Congo or Ethiopia, for example, have non-electrified populations of more than 60 million people each, but neither has ever been studied in an impact evaluation of electricity access. 
Figure 2: Studies per non-electrified population by country

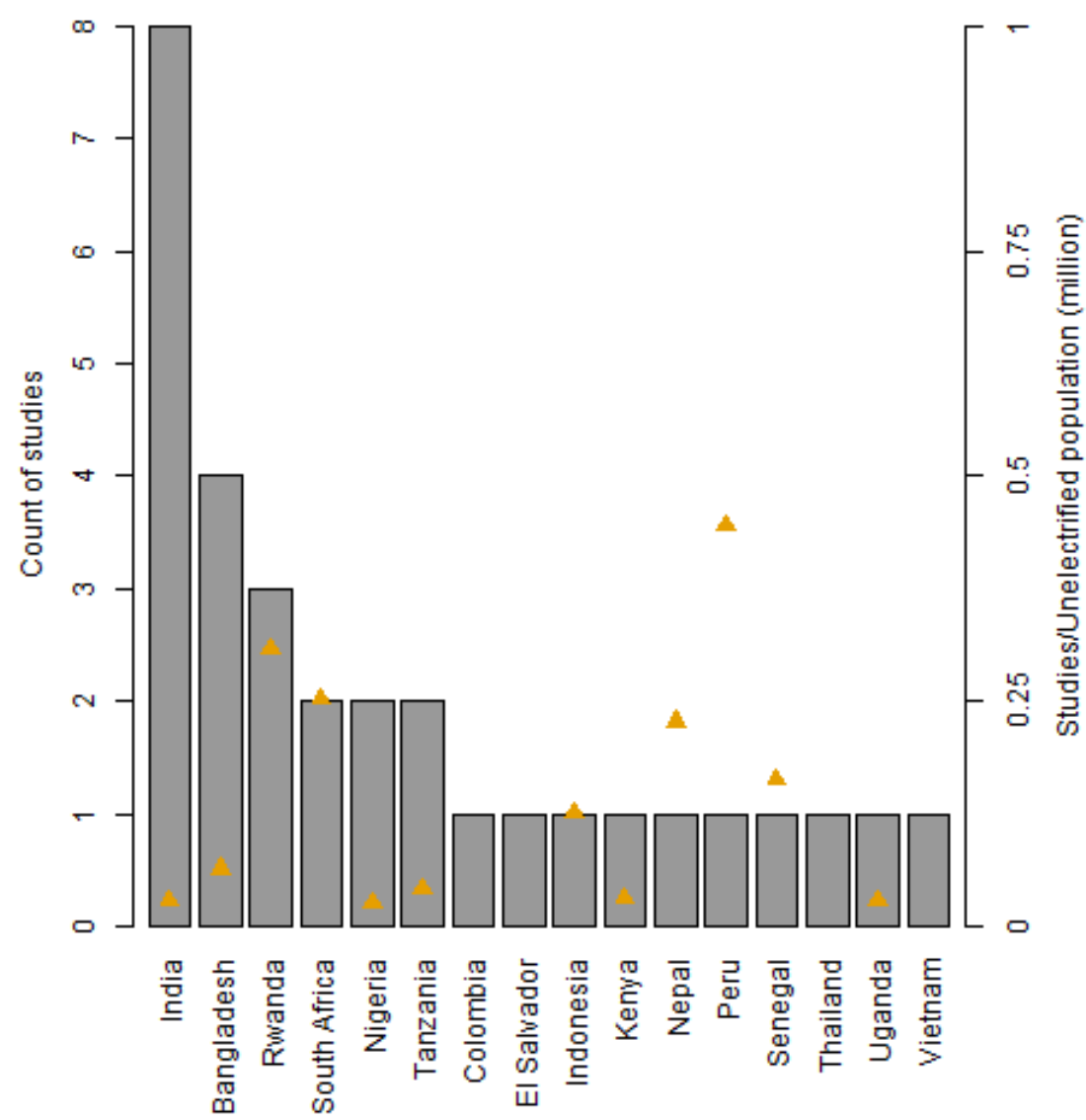

Bar plot. The gray bars show the count of studies in each country (left axis). The yellow triangles show a relative count as the share of studies per one million non-electrified population (right axis). Higher values denote a fairly large number of studies on a per capita basis. We exclude standardized values for Colombia, El Salvador, Thailand, and Vietnam because they are nearly 100\% electrified.

At the regional level, sub-Saharan Africa and South Asia have the lowest number of studies on a per capita basis. Even though most impact evaluations focus on these regions, the number of studies pales in view of the large non-electrified populations. On the other hand, the three studies in the Latin American and Caribbean region account for 19 million non-electrified people compared to 564 million in sub-Saharan Africa alone. 
Figure 3: Studies/non-electrified population by region

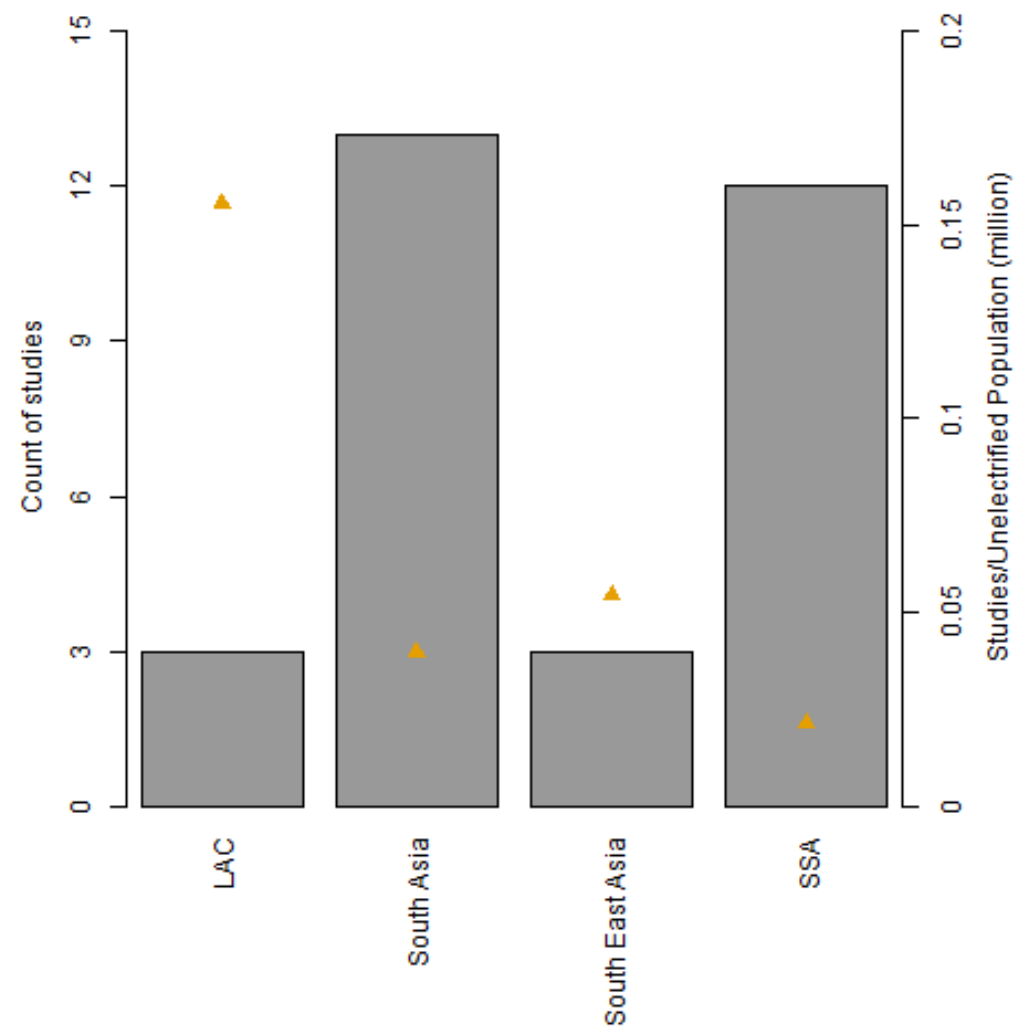

Bar plot. The gray bars show the count of studies in each region (left axis). The yellow triangles show a relative count as the share of studies per one million non-electrified population (right axis). Higher values denote a fairly large number of studies on a per capita basis. SSA=sub-Saharan Africa; LAC=Latin America and Caribbean.

\subsection{Representativeness within and across Countries}

So far, we have shown results by country and region. Here, we offer some preliminary insights from both geographic variation of where impact evaluations have been conducted within countries in our sample and how these countries in our sample compare across other countries in the developing world.

Appendix A provides information about the particular districts and regions within the countries in our sample where an impact evaluation was conducted. From our 31 studies overall, 13 base their impact evaluations on data from nationally representative surveys. Four studies rely on multiple sites across the country (Barkat et al. 2002; Bensch et al. 2011; Chaplin et al. 2017; Khandker et al. 2013), whereas roughly half of the studies in the sample assess impacts from more confined, local areas.

Take India for example. While three impact evaluations come from national surveys, the remaining evidence is from Gujarat (western state), Uttar Pradesh (northern state), and West Bengal (eastern state), three very different states in addressing energy poverty (Aklin et al. 2018). Bensch et al. $(2013,4)$ identify the Casamance region in Senegal, 
which "is largely separated from the rest of the country" and Kudo et al. (2017) study the effect of solar lanterns on academic performance in the chars river islands of Bangladesh. Focusing on these very remote, often deprived, and energy poor areas makes sense for studying the impacts of electricity access but generalizing the results to even the country level needs to be done with great care. Particular study sites within a country may or may not be representative of the country as a whole, and more research is needed to understand variation in the effectiveness of electricity access within countries.

Variation within countries aside, how representative are the countries that end up in our sample of electricity access impact evaluations? While a detailed analysis is beyond the scope of the paper, Figure 4 shows density plots for how developed (measured by logged GDP per capita), how democratic (measured by Polity IV regime type), and how densely populated (measured by logged population per $\mathrm{km}^{2}$ ) countries are. The gray plot shows the distribution for developing countries not in our sample and the blue area shows the density for countries included in our sample of impact evaluation studies.

Figure 4: Densities for countries excluded from and in the sample

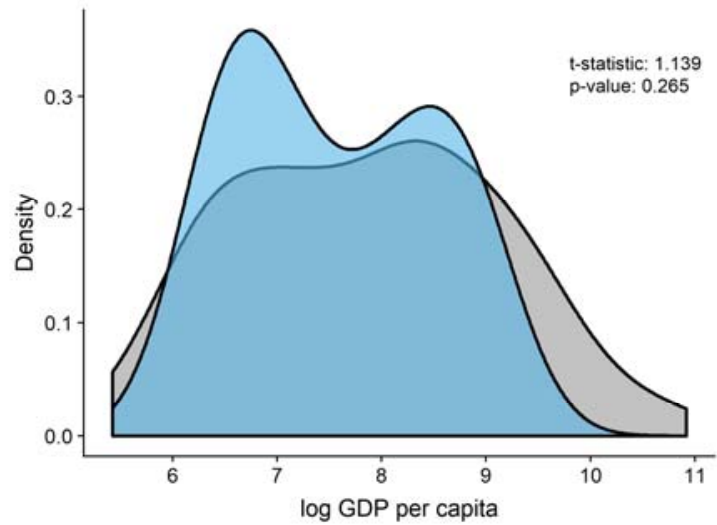

$\square$ Excluded $\square$ in sample

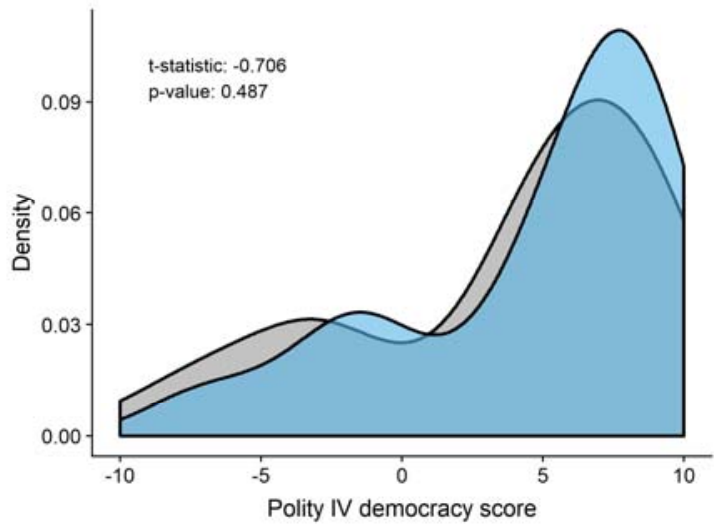

$\square$ Excluded $\square$ In sample

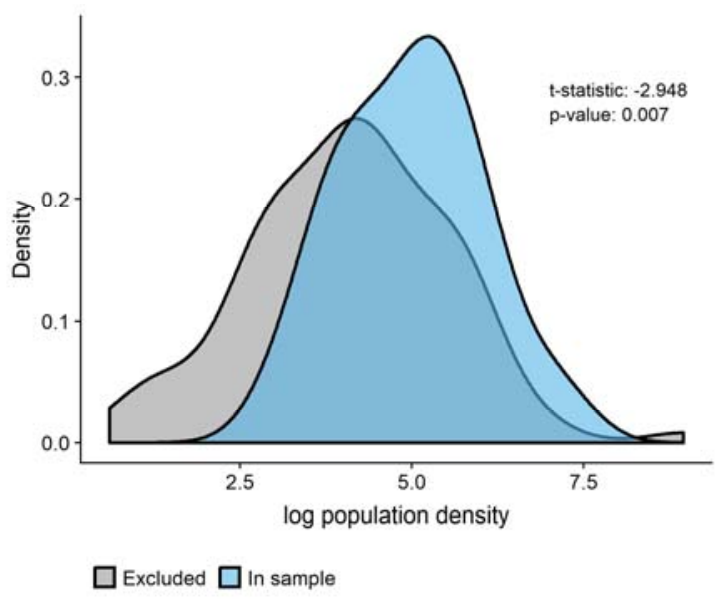

Density plots. The plots show densities for measures of economic development (logged GDP per capita), democratic institutions (Polity IV regime type), and population density (logged population per $\mathrm{km}^{2}$ ). For each 
variable, the gray density shows the distribution of the variable for countries that are not in our sample, while the blue density shows the distribution for countries included in our sample from the systematic review of impact evaluation studies. The $t$-statistic and the $p$-value that are shown are from simple t-tests for group means, where excluded countries are the 'control' group and included countries are the 'treatment' group.

The plots illustrate that in terms of economic development and democratic institutions countries are fairly comparable. Descriptively, countries in our sample are somewhat poorer $(p<0.265)$ and somewhat more democratic $(p<0.487)$ even though these differences across groups are not statistically significant in simple $t$-tests. Interestingly, countries for which rigorous impact evaluations exist and which therefore end up in our sample are more densely populated, and this difference is highly statistically significant $(p<0.007)$. This makes a lot of sense as high population densities are conducive to rural electrification because of economies of scale in central infrastructure provision by governments (Aklin et al. 2018). Rwanda, for which several impact evaluations exist (Bensch et al. 2011; Grimm et al. 2017; Lenz et al. 2017), is a case in point here, with one of the highest population densities around the world, and about seven times higher than that of neighboring Tanzania. This is another telling example about the importance of scope conditions for generalizing impact results from a geographically biased sample of impact evaluation studies of electricity access.

\subsection{Assessed Outcomes}

Across the 31 studies from our systematic review, 65 separate outcomes were assessed (Table 3). Household income (22 outcomes), education (19 outcomes), and energy expenditure (16 outcomes) were the most common. India has the most assessed outcomes overall with 14, followed by Rwanda with 12 and Bangladesh with 9 .

Table 3: Assessed outcomes (counts) by country

\begin{tabular}{|c|c|c|c|c|c|c|c|c|}
\hline$\#$ & Country & Region & Exp & $\mathrm{HH}$ income & $\mathrm{HH}$ savings & Business & Education & Total \\
\hline 1 & India & South Asia & 4 & 6 & 1 & 1 & 2 & 14 \\
\hline 2 & Bangladesh & South Asia & 3 & 3 & 2 & 0 & 4 & 12 \\
\hline 3 & Rwanda & SSA & 3 & 3 & 0 & 0 & 3 & 9 \\
\hline 4 & South Africa & SSA & 1 & 1 & 0 & 0 & 0 & 2 \\
\hline 5 & Nigeria & SSA & 0 & 1 & 0 & 1 & 0 & 2 \\
\hline 6 & Tanzania & SSA & 2 & 2 & 1 & 1 & 2 & 8 \\
\hline 7 & Colombia & $\mathrm{LAC}$ & 1 & 0 & 0 & 0 & 1 & 2 \\
\hline 8 & El Salvador & $\mathrm{LAC}$ & 1 & 0 & 0 & 0 & 0 & 1 \\
\hline 9 & Indonesia & South East Asia & 0 & 1 & 0 & 0 & 1 & 2 \\
\hline 10 & Kenya & $\mathrm{SSA}$ & 1 & 1 & 1 & 0 & 1 & 4 \\
\hline 11 & Nepal & South Asia & 0 & 1 & 0 & 0 & 0 & 1 \\
\hline 12 & Peru & LAC & 0 & 0 & 0 & 0 & 1 & 1 \\
\hline 13 & Senegal & SSA & 0 & 0 & 0 & 0 & 1 & 1 \\
\hline 14 & Thailand & South East Asia & 0 & 1 & 0 & 0 & 1 & 2 \\
\hline 15 & Uganda & SSA & 0 & 0 & 0 & 0 & 1 & 1 \\
\hline \multirow[t]{2}{*}{16} & Vietnam & South East Asia & 1 & 1 & 0 & 0 & 1 & 3 \\
\hline & Total & & 16 & 22 & 5 & 3 & 19 & 65 \\
\hline
\end{tabular}

Notes: Columns denote energy expenditure ('Exp'), household income ('HH income'), household savings ('HH savings'), business creation ('Business'), and education (Education'). SSA = sub-Saharan Africa; $\mathrm{LAC}=$ Latin America and Caribbean. 
In terms of total assessed outcomes, South Asia and sub-Saharan Africa lead the way, with 27 assessed outcomes each (Table 4). On a per-study basis, however, this picture changes somewhat. The number of outcomes per study is 2.25 in sub-Saharan Africa, 2.07 in South Asia, 2.33 in South East Asia, and 1.33 in Latin America and the Caribbean.

Table 4: Assessed outcomes (counts) by region

\begin{tabular}{llrrrrrr}
\hline$\#$ & Region & Exp & HH income & HH savings & Business & Education & Total \\
\hline 1 & South Asia & 7 & 10 & 3 & 1 & 6 & 27 \\
2 & SSA & 7 & 8 & 2 & 2 & 8 & 27 \\
3 & South East Asia & 1 & 3 & 0 & 0 & 3 & 7 \\
4 & LAC & 1 & 1 & 0 & 0 & 2 & 4 \\
\hline & Total & 16 & 22 & 5 & 3 & 19 & 65 \\
\hline
\end{tabular}

Notes: Columns denote energy expenditure ('Exp'), household income ('HH income'), household savings ('HH savings'), business creation ('Business'), and education (Education'). SSA = sub-Saharan Africa; $\mathrm{LAC}=$ Latin America and Caribbean.

\subsection{Assessed Impacts}

Studying assessed impacts by country, we can determine whether some countries see more positive results from impact evaluations than others. For this, we construct an index where positive impacts score +1 , neutral impacts score 0 , and negative impacts score 1 , weighted by the number of assessed impacts for each country. In coding neutral impacts we follow the interpretation of the authors in the original studies. Neutral impacts are, therefore, mostly estimates that are not statistically significant and are taken by the authors as null results.

Appendix B shows that failure to become statistically significant is, for most studies, not a result of imprecisely estimated confidence intervals but rather a consequence of point estimates being estimated fairly tightly around zero. The one exception is Furukawa (2014), who finds positive and negative impacts on educational outcomes depending on model specification, and concludes that the overall effect across models is neutral. We code it accordingly.

Out of all countries with more than three assessed outcomes, Bangladesh has the highest weighted impact score, with 11 positive impacts, a single neutral impact, and zero negative impacts (Table 5). However, it is difficult to see a definitive pattern across all countries, and regional breakdowns are more informative here. 
Table 5: Assessed impacts by country

\begin{tabular}{lllrrrr}
\hline$\#$ & Country & Region & Impacts & \multicolumn{2}{c}{ Score } \\
& & Negative & Neutral & Positive & \\
\hline 1 & India & South Asia & 0 & 4 & 10 & 0.71 \\
2 & Bangladesh & South Asia & 0 & 1 & 11 & 0.91 \\
3 & Rwanda & SSA & 0 & 3 & 6 & 0.67 \\
4 & South Africa & SSA & 0 & 0 & 2 & 1 \\
5 & Nigeria & SSA & 0 & 1 & 1 & 0.5 \\
6 & Tanzania & SSA & 0 & 1 & 7 & 0.87 \\
7 & Colombia & LAC & 0 & 1 & 1 & 0.5 \\
8 & El Salvador & LAC & 0 & 0 & 1 & 1 \\
9 & Indonesia & South East Asia & 1 & 0 & 1 & 0 \\
10 & Kenya & SSA & 0 & 3 & 1 & 0.25 \\
11 & Nepal & South Asia & 0 & 0 & 1 & 1 \\
12 & Peru & LAC & 0 & 0 & 1 & 1 \\
13 & Senegal & SSA & 0 & 0 & 1 & 1 \\
13 & Thailand & South East Asia & 0 & 1 & 1 & 0.5 \\
14 & Uganda & SSA & 0 & 1 & 0 & 0 \\
15 & Vietnam & South East Asia & 0 & 0 & 3 & 1 \\
\hline & Total & & 1 & 16 & 48 & 0.72 \\
\hline
\end{tabular}

Notes: Impacts are evaluated if they are negative $(-1)$, neutral $(0)$, or positive $(+1)$, and the score is then calculated as a weighted average. SSA = sub-Saharan Africa; LAC = Latin America and Caribbean.

Based on the weighted average score, South Asia (0.81) benefits the most from electrification access followed by Latin America and the Caribbean (0.75) and subSaharan Africa (0.66). South East Asia has low average impacts, but its score is brought down by a single negative impact. Electricity access is expected to usually improve socioeconomic development, so the negative impact may be surprising. It results from the negative impact of electricity access on female labor force participation in Indonesia found by Grimm et al. 2015. If we were to ignore this negative impact, the regional average impact score for South East Asia would become 0.83, which is comparable to the score in the neighboring South Asia region. This serves as a warning that positive impacts from electricity access as evidenced in Asia may be less likely to transfer to Africa in particular.

Table 6: Assessed impacts by region

\begin{tabular}{llrrrr}
\hline$\#$ & Region & Impacts & & Score \\
& & Negative & Neutral & Positive & \\
\hline 1 & South Asia & 0 & 5 & 22 & 0.81 \\
2 & SSA & 0 & 9 & 18 & 0.66 \\
3 & South East Asia & 1 & 1 & 5 & 0.57 \\
4 & LAC & 0 & 1 & 3 & 0.75 \\
\hline & Total & 1 & 16 & 48 & 0.72 \\
\hline
\end{tabular}

Notes: Impacts are evaluated if they are negative $(-1)$, neutral $(0)$, or positive $(+1)$, and the score is then calculated as a weighted average. SSA = sub-Saharan Africa; LAC = Latin America and Caribbean. 


\section{Conclusion}

Based on our systematic review, the geographic distribution of impact evaluations of electricity access in the developing world is heavily biased. Not only do we only find a small number of rigorous impact evaluation studies to begin with, the geographic spread of these studies is also fairly narrow. Much of what we know about impacts from electricity access is based on evidence from only 16 countries, ten of which have seen just a single study. Countries in our sample show a mix of impact evaluations based on nationally representative (survey) data and more local, subnational evidence. More disturbingly then, we show that the 16 studied countries in our sample are at least somewhat unrepresentative in terms of GDP per capita, democratic institutions, and population density. This becomes highly problematic because findings from one country may not apply to other countries because of political, economic, and cultural differences.

Relative to the size of non-electrified population, Latin America and the Caribbean has the most studies while sub-Saharan Africa has the fewest. Impacts of electricity access on socio-economic development reported by existing studies are on average more positive in South Asia and much less positive in sub-Saharan Africa. This is consistent with past concerns that findings from other regions do not necessarily travel to subSaharan Africa (Peters and Sievert 2016), where the electrification challenge is the greatest (Batinge et al. 2019).

Country-to-country differences notwithstanding, it seems plausible that findings generalize better within regions than across them. In the case of sub-Saharan Africa, for example, recent grid extension evaluations by Lee et al. (2018) in Kenya and Lenz et al. (2017) in Rwanda found little evidence that electrification helps alleviate poverty. In both cases, uptake of electricity connections and electric appliances for productive use was low. Both studies suggest that affordability can explain weak impacts. High connection costs and low household incomes, which are present in many sub-Saharan African countries, may hence put a limit to socio-economic development from electricity access in this region.

Our study points at some interesting avenues for future work. Future research could look into impact evaluations of electrification at the firm or regional level instead of the household level, drawing on a number of studies that have found some evidence for positive effects (e.g., Lipscomb et al. 2013; Rud 2012; Peters et al. 2011; Kassem 2018). Studies could also examine how persistent benefits from electrification access are. More importantly, we do not hypothesize why particular countries or regions have seen more impact evaluations and what drives positive impacts. Surely, the number of studies that pass the filters to end up in our sample is small. However, because the small number of studies that use statistical hypothesis testing to assess impacts for household electricity access is the result of a transparent and replicable systematic review of the literature this finding is itself an important insight for electricity access scholarship (Bayer et al. 2019). One important message of our paper here is therefore that very few rigorous impact evaluations of electricity access exist. 
In the future, researchers who design impact evaluations of electricity access and funding agencies who provide financial support should consider whether target countries, on a per capita basis, have seen many or few studies. Collectively, electricity access scholarship should strive to achieve balance across countries and regions. Prioritizing countries such as Ethiopia or the Democratic Republic of Congo with large non-electrified populations, yet not a single impact evaluation study, would help advance our understanding of electricity access impacts in the developing world. At a minimum, impact evaluation studies should offer an honest assessment of scope conditions of their findings to help adjudicate how likely and easily estimated impacts might travel across country borders (Peters et al 2018; Pritchett and Sandefur 2015).

Our findings also sound a warning to policymakers and development scholars not to expect that positive impacts from electrification access in one country are likely to be the same in another one. The success of electrification access in sub-Saharan Africa depends on different political, economic, and cultural factors than, say, in India. To design effective electrification policies that generate positive impacts, policymakers must have access to country-specific, contextually sensitive impact evaluations to not fall prey to the geographic bias we document in this paper. 


\section{Appendix A: List of Studies}

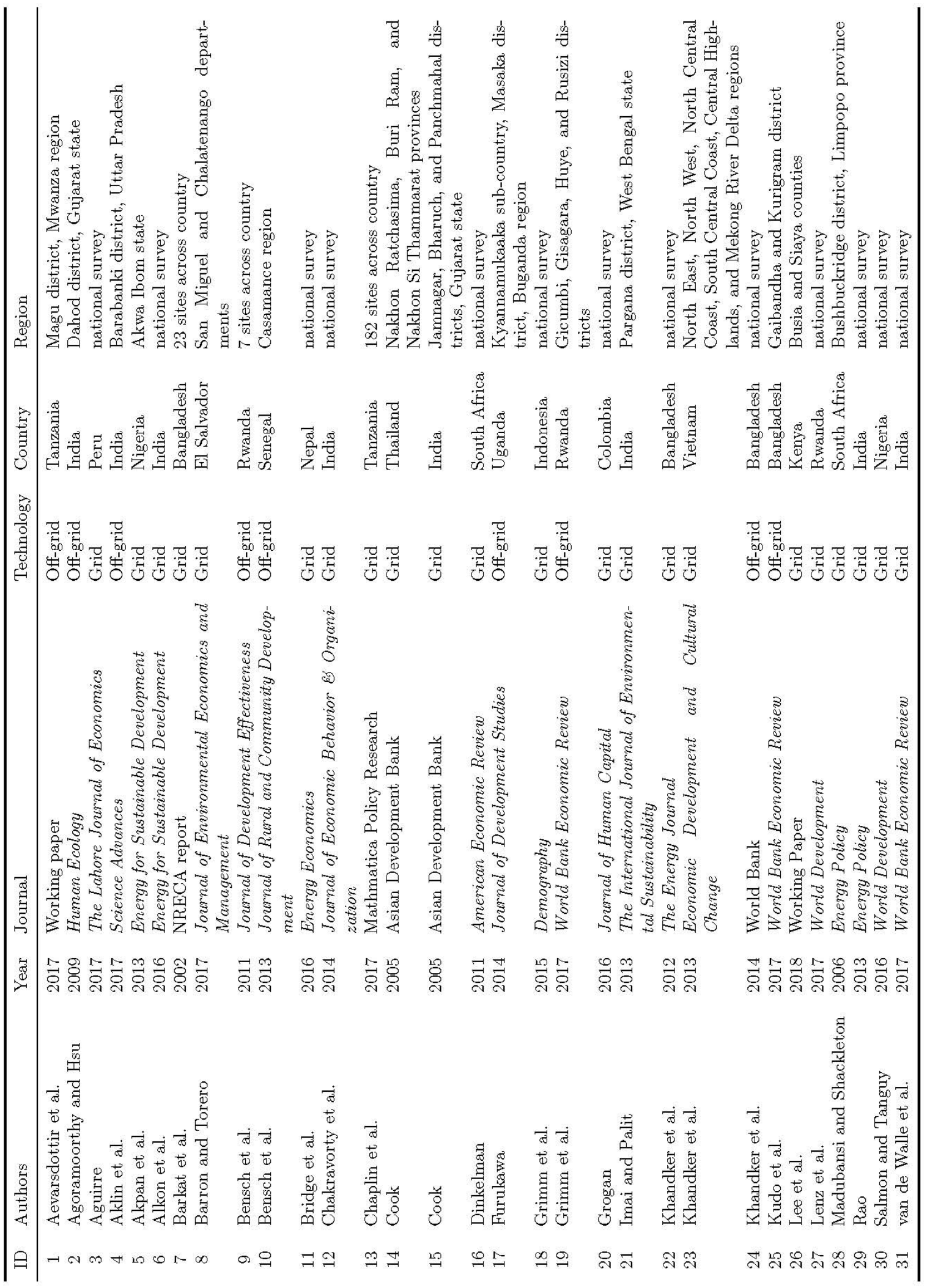




\section{Appendix B: Coding and Point Estimates of Neutral Impacts}

\begin{tabular}{clrlrrr}
\hline ID & Authors & Year & Outcome & Point Estimate & SE & $t$-value \\
\hline 1 & Aevarsdottir et al. & 2017 & Education & 2.402 & 1.62 & 1.482 \\
4 & Aklin et al. & 2017 & Household income & 192.81 & 174.24 & 1.106 \\
4 & Aklin et al. & 2017 & Household savings & 65.82 & 88.96 & 0.739 \\
4 & Aklin et al. & 2017 & Business creation & -0.01 & 0.02 & -0.500 \\
4 & Aklin et al. & 2017 & Education & -0.01 & 0.03 & -0.333 \\
5 & Akpan et al. & 2013 & Business creation & 0.0794 & 0.131 & 0.603 \\
9 & Bensch et al. & 2011 & Energy expenditures & 626.4 & 423.2 & 1.48 \\
14 & Cook & 2005 & Household income & Point estimates not reported for non-significant estimates \\
17 & Furukawa & 2014 & Education & Mixed positive and negative point estimates \\
19 & Grimm et al. & 2017 & Household income & 7249 & 12203 & 0.594 \\
20 & Grogan & 2016 & Household income & 0.1311 & 0.249 & 0.067 \\
24 & Khandker et al & 2014 & Household savings & 0.067 & 1.00 & 3.1 \\
26 & Lee et al. & 2018 & Household income & 5.1 & 851 & 0.067 \\
26 & Lee et al. & 2018 & Household savings & -0.08 & 0.100 & 1.645 \\
26 & Lee et al. & 2018 & Education & 0.633 & 1.406 & -0.800 \\
27 & Lenz et al. & 2017 & Household income & & 0.450 \\
\hline
\end{tabular}




\section{References}

Aklin, Michaël, Patrick Bayer, S.P. Harish, and Johannes Urpelainen (2018). Escaping the energy poverty trap: When and how governments power the lives of the poor. Cambridge, MA: MIT Press.

Asian Development Bank (2012). "Developing impact evaluation methodologies, approaches, and capacities in selected developing member countries." Manila: Asian Development Bank report (2012). https://www.adb.org/sites/default/files/project-document/75771/46185-001-reg-tar.pdf

Barkat Abul, S.H. Khan, M. Rahman, S. Zaman, A. Poddar, S. Halim, N.N. Ratna, M. Majid, A.K.M. Maksud, A. Karim, and S. Islam (2002). "Economic and social impact evaluation study of the rural electrification program in Bangladesh." NRECA report.

Barron, Manuel and Maximo Torero (2014). "Electrification and time allocation: Experimental evidence from northern El Salvador." Munich Personal RePEc Archive Paper No. 63782.

Batinge, Benjamin, Josephine Kaviti Musango, and Alan C. Brent (2019). "Perpetuating energy poverty: Assessing roadmaps for universal energy access in unmet African electricity markets." Energy Research \& Social Science 55: 1-13.

Bayer, Patrick, Ryan Kennedy, Joonseok Yang, and Johannes Urpelainen (2019). "The need for impact evaluation in electricity access research." Working paper.

Bensch, Gunther, Jochen Kluve, and Jörg Peters (2011). "Rural electrification in Rwanda: An impact assessment using matching techniques." Journal of Development Effectiveness 3 (4): 567 588.

Bensch, Gunther, Jörg Peters, and Maximiliane Sievert (2017). "The lighting transition in rural Africa-From kerosene to battery-powered LED and the emerging disposal problem." Energy for Sustainable Development 39: 13-20.

Bensch, Gunther, Michael Grimm, Maximilian Huppertz, Jörg Langbein, and Jörg Petters (2018). "Are promotion programs needed to establish off-grid solar energy markets? Evidence from rural Burkina Faso." Renewable and Sustainable Energy Reviews 90: 1060-1068.

Bernard, Tanguy (2012). "Impact analysis of rural electrification projects in sub-Saharan Africa." The World Bank Research Observer 27 (1): 33-51.

Chaplin, Duncan, Arif Mamun, Ali Protik, John Schurrer, Divya Vohra, Kristine Bos, Hannah Burak, Laura Meyer, Anca Dumitrescu, Christopher Ksoll, and Thomas Cook (2017). "Grid electricity expansion in Tanzania by MCC: Findings from a rigorous impact evaluation." Mathematica Policy Research.

Crespo, Anna Risi Vianna and Oliver Azuara Herrera (2017). "IDB's impact evaluations: production, use and influence." Washington, DC: Inter-American Development Bank, 2017. https://publications.iadb.org/en/idbs-impact-evaluations-production-use-and-influence

Furukawa, Chishio (2014). "Do solar lamps help children study? Contrary evidence from a pilot study in Uganda." The Journal of Development Studies 50 (2): 319-241. 
Global Tracking Framework (2017). "Global Tracking Framework 2017: Progress Toward Sustainable Energy.” https://trackingsdg7.esmap.org/

Grimm, Michael, Robert Sparrow, and Luca Tasciotti (2015). "Does electrification spur the fertility transition? Evidence from Indonesia." Demography 52 (5): 1773-1796.

Grimm, Michael, Anicet Munyehirwe, Jörg Peters, and Maximiliane Sievert (2017). "A first step up the energy ladder? Low cost solar kits and household's welfare in rural Rwanda." The World Bank Economic Review 31 (3): 631-649.

Grogan, Louise (2016). "Household electrification, fertility, and employment: Evidence from hydroelectric dam construction in Colombia." Journal of Human Capital 10 (1): 109-159.

Kassem, Dana (2018). "Does electrification cause industrial development? Grid expansion and firm turnover in Indonesia." CRC TR 224 working paper. https://www.crctr224.de/en/researchoutput/discussion-papers/discussion-paper-archive/2018/does-electrification-cause-industrialdevelopment-grid-expansion-and-firm-turnover-in-indonesia-dana-kassem/view

Khandker, Shahidur R., Douglas F. Barnes, and Hussain A. Samad (2012). "The welfare impacts of rural electrification in Bangladesh." The Energy Journal 33: 187-206.

Khandker, Shahidur R., Douglas F. Barnes, and Hussain A. Samad (2013). "The welfare impacts of rural electrification: A panel data analysis from Vietnam." Economic Development and Cultural Change 61 (3): 659-692.

Khandker, Shahidur R., Hussain A. Samad, Zubair K. M. Sadeque, Mohammed Asaduzzaman, Mohammad Yunus, and A. K. Enamul Haque (2014). "Surge in Solar-Powered Homes: Experience in Off-Grid Rural Bangladesh." Washington, DC: World Bank. http://documents.worldbank.org/curated/en/871301468201262369/Surge-in-solar-poweredhomes-experience-in-off-grid-rural-Bangladesh.

Kudo Yuya, Abu S. Shonchoy, and Kazushi Takahashi (2017). "Can solar lanterns improve youth academic performance? Experimental evidence from Bangladesh." World Bank Economic Review lhw073.

Lawry, Steven, Cyrus Samii, Ruth Hall, Aaron Leopold, Donna Hornby, and Farai Mtero (2016). "The impact of land property rights interventions on investment and agricultural productivity in developing countries: a systematic review." Journal of Development Effectiveness 1: 61-81.

Lee, Kenneth, Edward Miguel, and Catherine Wolfram (2018). "Experimental Evidence on the Economics of Rural Electrification.” NBER Working Paper 22292.

Lenz, Luciane, Anicet Munyehirwe, Jörg Peters, and Maximiliane Sievert (2017). "Does largescale infrastructure investment alleviate poverty? Impacts of Rwanda's electricity access roll-out program." World Development 89: 88-110.

Lipscomb, Molly, A. Mushfiq Mobarak, and Tania Barham (2013). Development Effects of Electrification: Evidence from the Topographic Placement of Hydropower Plants in Brazil. American Economic Journal: Applied Economics 5(2): 200-231. 
Mural, Rashmi, Sangeeta Malhotra, Debajit Palit, and Krishnapada Sasmal (2015). "Sociotechnical assessment of solar photovoltaic systems implemented for rural electrification in selected villages of Sundarbans region of India," AIMS Energy 3(4): 612-634.

Peters, Jörg, Colin Vance, and Marek Harsdorff (2011). Grid extension in rural Benin: Micromanufacturers and the electrification trap. World Development 39(5): 773-783.

Peters, Jörg and Maximiliane Sievert (2016). "Impacts of rural electrification revisited: The African context." Journal of Development Effectiveness 8 (3): 327-345.

Peters, Jörg, Jörg Langbein, and Gareth Roberts (2018). "Generalization in the Tropics: Development policy, randomized controlled trials, and external validity." World Bank Research Observer 33(1): 34-64.

Pritchett, Lant, and Justin Sandefur (2015). "Learning from experiments when context matters." American Economic Review 105(5): 471-475.

Pueyo, Ana and Mar Maestre (2019). "Linking energy access, gender, and poverty: A review of the literature on productive uses of energy." Energy Research \& Social Science 53: 170-181.

Rud, Juan Pablo (2012). Electricity Provision and Industrial Development: Evidence from India. Journal of Development Economics 97(2): 352-367.

Salmon, Claire, and Jeremy Tanguy (2016). "Rural electrification and household labor supply: Evidence from Nigeria." World Development 82: 48-68.

Samad, Hussain A., Shahidur R. Khandker, M. Asaduzzaman, and Mohammad Yunus (2013). "The benefits of solar home systems: An analysis from Bangladesh." World Bank Policy Research Working Paper (6724). Washington, DC: World Bank.

Sovacool, Benjamin K., Joon Axsen, and Steve Sorrell (2018). "Promoting novelty, rigor, and style in energy social science: Towards codes of practice for appropriate methods and research design." Energy Research \& Social Science 45: 12-42.

Stojanovski, Ognen, Mark Thurber, George Muwowo, Frank A. Wolak, and Kat Harrison (2018). "Assessing opportunities for solar lanterns to improve educational outcomes in rural off-grid regions: Challenges and lessons from a randomized controlled trial." Asian Development Bank Working Paper (910). Tokyo: Asian Development Bank.

Vijayaraghavan, Maya and Garrett Kilroy (2018). Impact of cost-shared water supply services on household welfare in small towns: Ex post impact evaluation of a project in Nepal. Manila: Asian Development Bank. https://www.adb.org/sites/default/files/evaluation-document/237456/files/ienep-stwsssp.pdf.

Waddington, Hugh, Edoardo Masset, and Emmanuel Jimenez (2018). "What have we learned after ten years of systematic reviews in international development?" Journal of Development Effectiveness 1: 1-16.

World Bank (2013). "World Bank Group Impact Evaluations: Relevance and Effectiveness." Washington, DC: World Bank. 
https://openknowledge.worldbank.org/bitstream/handle/10986/13100/757230PUB0EPI0001300 OPubdate0209013.pdf?sequence=1\&isAllowed=y

World Bank (2017). "State of Electricity Access Report." Washington, DC: World Bank. http://documents.worldbank.org/curated/en/364571494517675149/pdf/114841-REVISED-

JUNE12-FINAL-SEAR-web-REV-optimized.pdf 